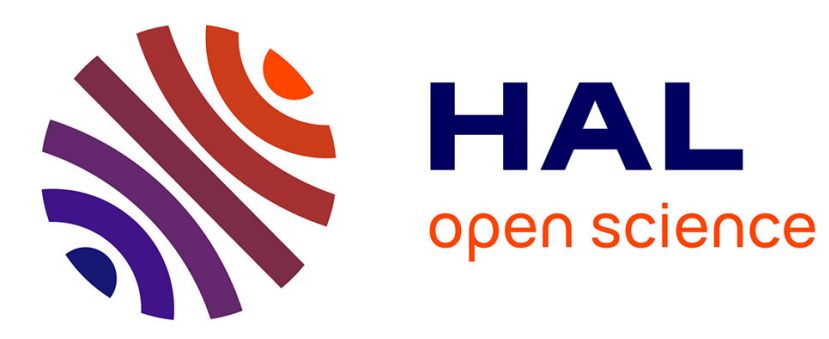

\title{
Fracture in Augmented Reality
}

Nazim Haouchine, Alexandre Bilger, Jeremie Dequidt, Stephane Cotin

\section{To cite this version:}

Nazim Haouchine, Alexandre Bilger, Jeremie Dequidt, Stephane Cotin. Fracture in Augmented Reality. SIGGRAPH [Poster], Aug 2015, Los Angeles, United States. hal-01191090

\section{HAL Id: hal-01191090 \\ https://inria.hal.science/hal-01191090}

Submitted on 1 Sep 2015

HAL is a multi-disciplinary open access archive for the deposit and dissemination of scientific research documents, whether they are published or not. The documents may come from teaching and research institutions in France or abroad, or from public or private research centers.
L'archive ouverte pluridisciplinaire HAL, est destinée au dépôt et à la diffusion de documents scientifiques de niveau recherche, publiés ou non, émanant des établissements d'enseignement et de recherche français ou étrangers, des laboratoires publics ou privés. 


\section{Fracture in Augmented Reality}

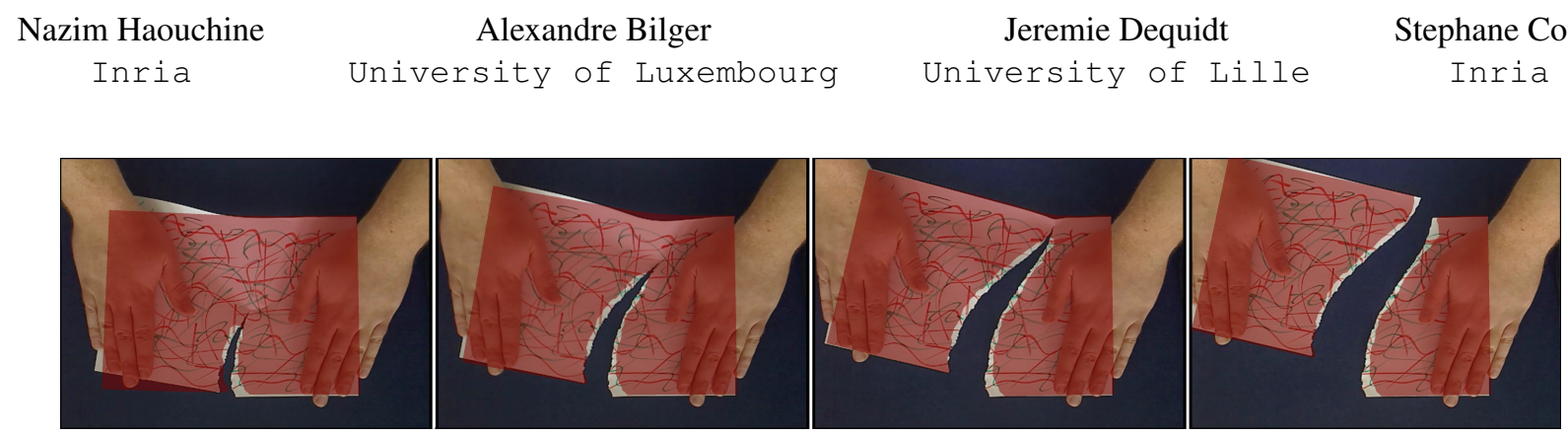

Figure 1: Selected frames of an Augmented Reality sequence of a paper undergoing a fracture.

\section{Introduction and Related Works}

The considerable advances in Computer Vision for hand and finger tracking made it possible to have several sorts of interactions in Augmented Reality systems (AR), such as object grasping, object translation or surface deformation [Chun and Höllerer 2013]. However, no method has yet considered interaction than involves topological changes of the augmented model (like mesh cutting).

Most of the time, the cut is purely virtual, which means that the point of incision is generated using computer-generated simulation and generic fracture patterns [Müller et al. 2013]. Some methods propose to use haptic devices for interaction with the augmented object [Spillmann and Harders 2012]. The benefit of such methods is that the device can accurately output the position of the instrument to find the point of fracture.

We propose in this study an image-guided mesh cutting method to handle real-time augmentation of paper tearing. This method relies on the combination of visually-based fracture tracking algorithm and a physics-based model that is dynamically superimposed on the image. To the best of our knowledge, no similar method has yet been proposed.

\section{Methods}

In order to correctly reproduce the fracture of the object, the point of fracture have to be efficiently detected. The fracture point is detected using a simple background substraction stage, thus, we assume having a uniform background. Once the fracture path is detected, the fracture point has to be tracked over frames. Since the tearing will impose a direction of fracture, we consider the fracture point as the summit of the breach created from tearing, this will allow us to easily and efficiently track the fracture point at each frame.

The paper-like model is a triangulated 3D mesh of hexagonally connected vertices that will undergone both fracture and affine transformation. For that purpose, in addition to track the point of fracture, we define a set $A=\left\{a_{i} \in \mathbb{R}^{2}\right\}$ of anchors points that will constrain

*e-mail:stephane.cotin@inria.fr the cut part of the paper. This set of anchors points are extracted and than tracked over frames using optical flow technique. At initialization each anchor $a_{i}$ from the image is mapped on the triangular mesh using the barycentric coordinates of the neighbouring vertices $V=\left\{v_{i} \in \mathbb{R}^{3}\right\}$ of the mesh.

One of the major challenge of the mesh fracture stage is to be able to update the topology in real-time. This can be done either by subdividing triangles (and take-care of ill-formed triangles) or by removing triangles on a fine enough mesh. We choose the latter approach, for which we know more elegant and more robust topological approaches exist but are beyond the scope of this study.

In order to detect the triangle to remove, we use ray-casting technique. At initialization, the fracture point $p=(x, y)$ is projected on the set of triangles $T=\left\{t_{i} \in \mathbb{R}^{3}\right\}$, the intersected triangle $t_{i}$ is deleted and the topology is updated by re-assigning the vertices to the right triangles. Once the first triangle is removed, if the raycasting finds a new triangle to remove in the next frame, we remove also the triangles on the geodesic path between both triangles. This enables the fracture to be continuous if the triangles size is less than the maximum distance of the fracture point between two frames.

The Figure 1 illustrates the augmentation of the paper during the tearing where it shows the robust tracking of the fracture point and the correct alignment of the mesh constrained by the anchors points. The overlay is achieved without impacting the framerate of the video acquisition (around $17 \mathrm{fps}$ ) while using a triangle mesh composed of 5800 triangles. We quantify the registration error by computing the distance between the silhouette of the paper-like model and the actual boundaries extracted in the image. We report a relatively small registration error of less than $4 \%$ w.r.t the whole surface registration. Future work will address cutting of volumetric 3D model and will consider non-rigid and elastic object.

\section{References}

Chun, W. H., AND Höllerer, T. 2013. Real-time hand interaction for augmented reality on mobile phones. In Intelligent User Interfaces, ACM, 307-314.

Müller, M., Chentanez, N., And Kim, T.-Y. 2013. Real time dynamic fracture with volumetric approximate convex decompositions. ACM Transactions on Graphics (TOG) 32, 4, 115.

SPILlmanN, J., AND HARdERS, M. 2012. Robust interactive collision handling between tools and thin volumetric objects. IEEE Transactions on Visualization and Computer Graphics 18, 8 (Aug.), 1241-1254. 